\title{
Cuidado e Artes Circenses: 0 circo no cotidiano de uma instituição de saúde mental
}

\section{Care and Circus Arts: The circus in the daily life of a mental health institution}

\section{Cuidado y Artes Circenses: el circo en el cotidiano de una institución de salud mental}

\author{
Luiza Fernandes Barros* \\ Prefeitura Municipal de Barbacena, Barbacena, Minas Gerais, Brasil
}

\section{Walter Melo**}

Universidade Federal de São João del-Rei - UFSJ, São João del-Rei, Minas Gerais, Brasil

\section{RESUMO}

Este artigo busca compreender algumas ressonâncias da prática de atividades circenses no cotidiano de uma instituição de saúde mental, a partir da inserção em um Centro de Atenção Psicossocial Álcool e outras Drogas, serviço substitutivo à lógica manicomial, pautado na atenção psicossocial e em ações territoriais. Nesse sentido, o trabalho parte de uma contraposição ao modelo biomédico, estabelecendo reflexões sobre as práticas de circo a partir das noções de cuidado, de circo social e de trabalho vivo em ato. Os encontros circenses fundamentaram-se em técnicas de malabarismo, acrobacia e equilibrismo, por meio dos quais foram consolidadas relações afetivas, cooperação e cuidado mútuo. O afeto mostrou-se como um dos pilares das atividades, pelo qual se estabeleceram relações de trocas, de cumplicidade e de confiança, além de possibilitar surpreendentes evoluções técnicas. O trabalho de campo, apreendido por meio de observação participante, diários de campo, fotografias, filmagens e entrevistas semiestruturadas, proporcionou pontuar e refletir uma série de ressonâncias da prática de artes circenses em uma instituição de saúde mental, sendo tratadas neste artigo: a relação risco/segurança, evolução técnica e cuidado.

Palavras-chave: circo, cuidado, CAPS, atenção psicossocial, artes circenses.

\begin{abstract}
This article aims to understand some resonances of the practice of circus activities in the everyday life of a mental health institution, from the insertion in a Center for Psychosocial Care Alcohol and other Drugs, a substitute service to the asylum logic, based on psychosocial attention and territorial actions. In this sense, the work opposes to the biomedical model, establishing reflections on the circus practices from the notions of care, social circus and live work in act. The circus meetings were based on
\end{abstract}


techniques of juggling, acrobatics and balancing, through which they were consolidated affective relationships, cooperation and mutual care. Affection was shown as one of the pillars of the activities, through which relations of exchange, complicity and trust were established, as well as making possible technical evolutions. Fieldwork, seized through participant observation, field journals, photographs, filming and semi-structured interviews, provided a point of reference and reflection of a series of resonances of the practice of circus arts in a mental health institution, being dealt with in this article: the risk/safety relationship, technical evolution and care.

Keywords: circus, care, CAPS, psychosocial attention, circus arts.

\section{RESUMEN}

Este artículo busca comprender algunas resonancias de la práctica de actividades circenses en el cotidiano de una institución de salud mental, a partir de la inserción en un Centro de Atención Psicosocial Alcohol y otras Drogas, servicio sustitutivo a la lógica manicomial, pautado en la atención psicosocial y en acciones territoriales. En ese sentido, el trabajo parte dese efectúa una contraposición al modelo biomédico, estableciendo reflexiones sobre las prácticas de circo a partir de las nociones de cuidado, de circo social y de trabajo vivo en acto. Los encuentros circenses se fundamentaron en técnicas de malabarismo, acrobacia y equilibrismo, a través de los cuales se consolidaron relaciones afectivas, cooperación y cuidado mutuo. El afecto se mostró como uno de los pilares de las actividades, por el cual se establecieron relaciones de intercambio, de complicidad y de confianza, además de posibilitar sorprendentes evoluciones técnicas. El trabajo de campo, incautado por medio de observación participante, diarios de campo, fotografías, filmaciones y entrevistas semiestructuradas, proporcionó puntuar y reflejar una serie de resonancias de la práctica de artes circenses en una institución de salud mental, siendo tratadas en este artículo: la relación riesgo/seguridad, evolución técnica y cuidado.

Palabras clave: circo, cuidado, CAPS, atención psicosocial, artes circenses.

O campo da saúde mental se apresenta como um processo social complexo, caracterizado pela interação, convergente ou divergente, entre quatro dimensões: jurídico-política, técnico-assistencial, teórico-conceitual e sociocultural. A dimensão jurídico-política está consolidada a partir da Rede de Atenção Psicossocial (RAPS), instituída pela Portaria n. 3.088 (2011), da Lei n. 10216 (2001) e da Portaria n. 336 (2002), coerentes com a Constituição Federal (Brasil, 1988) e com a Lei n. 8080 (1990): "Trata-se de uma luta pela inclusão de novos sujeitos de direito e novos direitos para os sujeitos em sofrimento mental" (Amarante, 2007, p. 70). A dimensão técnicoassistencial inscreve o Centro de Atenção Psicossocial (CAPS) como dispositivo privilegiado de ações territoriais, organizadas por equipe interdisciplinar, destinadas ao acolhimento, cuidado, trocas sociais e produção de subjetividade. A dimensão teórico-conceitual produz uma inflexão, abandonando as noções de degenerescência e periculosidade, passando a trabalhar a partir dos conceitos de território, atenção psicossocial, cidadania e cuidado. A dimensão sociocultural instaura um diálogo permanente com a sociedade, 
através de ações pautadas na arte, na economia solidária, informação, debates, estudos, tendo como ponto de partida a produção cultural e artística dos usuários, familiares e técnicos, a fim de refletir sobre a loucura, sobre os hospitais psiquiátricos e a saúde mental (Amarante, 2007).

Apesar de dialogar com as quatro dimensões, este trabalho possui ênfase nesta última, a dimensão sociocultural, na medida em que parte de uma ação que envolve a própria construção cultural dos atores sociais envolvidos no processo de saúde, por meio de práticas circenses. Nesta dimensão, a atuação proposta compreende-se na esfera da arte, implicada em uma transformação cultural.

A relação entre as artes e o campo da saúde mental tem se mostrado como uma das principais características da dimensão sociocultural da Reforma Psiquiátrica brasileira (RPb) (Melo \& Ferreira, 2011), tendo Nise da Silveira $(1981,1992)$ como importante ator social (Melo, 2001, 2005; Mello, 2014). Nesse sentido, podemos destacar os trabalhos que Nise da Silveira desenvolveu em diálogo com diversos artistas: com Leon Hirszman no cinema (Avellar, 2001, 2011; Melo, 2010a), com Rubens Corrêa no teatro (Melo, 2010b) e com os artistas concretos nas artes plásticas (Melo, 2011). Seguindo essa tradição, diversos trabalhos foram desenvolvidos no âmbito da RPb, dentre os quais: os grupos de teatro Os Nômades, do Espaço Artaud (Melo, 2012; Sá, 2010, 2011), Pirei na Cenna, vinculado ao Centro de Teatro do Oprimido (CTO) (Conceição, 2010) e Sapos e Afogados (Oliveira, Melo, \& Vieira-Silva, 2017), o grupo musical Harmonia Enlouquece (Dantas, 2010, 2016), o bloco carnavalesco Tá Pirando, Pirado, Pirou (Xisto 2009, 2011, 2012), o desfile do 18 de maio em Belo Horizonte (Moura, 2011; Moura \& Passos, 2012), o grupo de ações poéticas Sistema Nervoso Alterado (Wanderley, 2011), dentre outros.

O presente artigo tem como objetivo refletir sobre a inserção das artes circenses no campo da saúde mental, a partir da compreensão de algumas ressonâncias da prática do circo no cotidiano de um Centro de Atenção Psicossocial Álcool e outras Drogas (CAPS ad). A inclusão de atividades circenses em instituições de saúde mental dialoga diretamente com os preceitos da $R P b$, tendo como parâmetros a atenção psicossocial (Amarante, 2007), a produção de saúde e os processos de cuidado (Merhy, 1998; Merhy \& Franco, 2003).

Por se tratar de uma manifestação da cultura corporal, o circo permite construir uma rica variedade de movimentações, desde formas bem simples até as mais complexas, além de apresentar grandes contribuições no que diz respeito aos domínios cognitivo, motor, afetivo/emocional e social (Santos, Belluci, Fajtlowicz, \& Bechara, 2012). Cognitivo no que se refere ao desenvolvimento da atenção, concentração, raciocínio, imaginação, memorização e 
percepção. Motor, pois são atividades que contribuem para o ganho de tônus muscular e hábitos posturais, além da melhoria das capacidades físicas (flexibilidade muscular, mobilidade articular, potência, etc). Emocional, pois as técnicas circenses desenvolvem aspectos como coragem, ousadia, determinação, autodomínio, autoconfiança e perseverança. E social, pois são práticas que implicam relações pautadas na responsabilidade, iniciativa, disciplina, respeito, cooperação, auxílio mútuo e espírito crítico.

Nesse sentido, além de trabalhar vários aspectos corporais, o circo permite acessar e construir uma série de formas de se relacionar com o próprio corpo, com o corpo do outro, com objetos e aparelhos. Para além de uma atividade com caráter esportivo, o circo é uma arte, uma expressão humana, um meio para criação, para acesso à magia, ao fantástico, ao novo: "Isso ocorre porque as manifestações da cultura corporal circense propiciam ao corpo experimentar uma rede de signos (liberdade, desafio, aventura) a partir da vivência das diversas sensações (medo, suspense e alegria)" (Santos et al., 2012, p. 82).

Os estudos sobre circo no campo da saúde mental são relativamente novos e ainda pouco documentados. Assim, temos trabalhos que as abordam no âmbito da saúde e da educação inclusivas (Silva, 2012) e, diretamente relacionadas ao campo da saúde mental, temos pesquisas referentes à arte da palhaçaria (Assis, 2010; Barboza, 2016; Gómez, 2017). A inclusão de doutores palhaços em ambientes de tratamentos se caracteriza como a principal marca da relação saúde/circo.

Além do emblemático Dr. Hunter Doherty "Patch" Adams, médico norte-americano, que atua desde 1972, constata-se historicamente a presença de outros palhaços nos hospitais. Segundo Castro (2005), Michael Christensen, diretor do Big Apple Circus de Nova York, apresentou-se em um hospital em 1986 e, ao saber sobre as crianças internas que não puderam assistir sua apresentação, foi de leito em leito improvisando sobre a realidade do hospital e seus pequenos pacientes. Estava criada a semente do projeto Clown Care Unit. O brasileiro Wellington Nogueira participou do grupo de 1988 a 1991 e, quando retornou ao Brasil, criou os Doutores da Alegria.

A presente proposta difere dessas perspectivas em três aspectos: (1) o público-alvo é, exclusivamente, de um serviço de saúde mental (CAPS ad de um município do interior de Minas Gerais); (2) as atividades circenses são praticadas pelos usuários e funcionários da instituição; (3) não está fundamentada na técnica do palhaço, mas em práticas de acrobacia, malabarismo e equilibrismo. A escolha por essas modalidades se deu pelo fato de, tradicionalmente, elas serem consideradas disciplinas básicas para o aprendizado circense. Básicas no sentido de dar base, pois permitem o treinamento do equilíbrio, ganho de força, flexibilidade, consciência de corpo e movimento, 
coordenação motora, noção de giro, entre outros aspectos importantes para o desenvolvimento das artes circenses. Na Escola Nacional de Circo (ENC), por exemplo, essas modalidades são exigidas a todos os alunos, que somente após cumpri-las terão possibilidade de montar sua grade com outras disciplinas (Santos, 2016).

As atividades no CAPS ad foram propostas de maneira livre, ou seja, a participação não foi obrigatória, e ocorreram de 12 de junho a 20 de setembro de 2017, duas vezes por semana, totalizando 27 práticas circenses em 100 dias. Posteriormente, foram realizadas 12 entrevistas, sendo sete com usuários e cinco com profissionais da instituição, sobre as percepções que tiveram em relação às atividades e suas possíveis ressonâncias. Além disso, foram efetuadas observações do cotidiano da instituição, materializadas no diário de campo, e as atividades circenses foram fotografadas e filmadas. Assim, o corpus da pesquisa foi configurado e cada procedimento metodológico proporcionou o acesso a importantes elementos de análise.

Após o período de práticas circenses e concluídas as entrevistas, o material foi organizado em categorias e analisado a partir da hermenêutica (Gadamer, 2002), criando condições para a implicação dos pesquisadores durante o trabalho de campo, mas também na interpretação do material, levando em consideração as perspectivas e pré-conceitos de pesquisadores e participantes. Assim, ao lidarmos com os dados e com os afetos, percebemos a repetição de determinados aspectos, evidenciados nas falas, observações e convivência. Dessa maneira, foram criadas oito categorias a partir das ressonâncias que as atividades circenses produziram nos frequentadores - profissionais e usuários - do CAPS ad, sendo elas: (1) relação risco/segurança, (2) evolução técnica, (3) cuidado, (4) implicação no tratamento, (5) quebra de estigmas, (6) "agora eu não uso droga, eu uso patins, perna de pau", (7) reconhecimento do lugar das oficinas no serviço de saúde mental e (8) aspectos corporais. Cabe ressaltar que todas essas categorias estão intimamente relacionadas. Neste artigo, abordaremos os três aspectos iniciais: a relação risco/segurança, a evolução técnica e o cuidado. Esses aspectos serão analisados a partir das noções de cuidado (Merhy, 1997; Merhy \& Franco, 2003), de circo social (Cassoli, 2006; Gallo, 2010a, 2010b; Lafortune \& Bouchard, 2011) e de trabalho vivo em ato (Merhy, 1997, 2014; Merhy \& Franco, 2003), concebidos, respectivamente, como conceito de observação direta, conceito de observação indireta e conceito teórico (Minayo, 2007). 


\section{A Relação Risco/Segurança}

Nas mais de 1500 horas de curso na ENC, além das aulas diretamente relacionadas às atividades circenses, são enfatizados os ensinamentos para que sejam aprimorados os aspectos de segurança (Santos, 2016). Para tal, foi realizado, dentre outras atividades, 0 curso NR-35: Prevenção de Acidentes e Sistemas de Proteção contra Quedas para os Trabalhos em Altura, ministrado por uma empresa especializada. Mais do que o aprendizado, cria-se uma cultura de segurança. Esse princípio básico da vida circense foi levado para as atividades no CAPS ad.

A novidade sobre pesquisas relacionadas às atividades circenses criou alguns receios na comunidade acadêmica, com temores sobre os riscos apresentados aos usuários do CAPS ad. Dessa maneira, o termo cuidado estava ligado, inicialmente, a dois aspectos negativos: receio, na universidade; e perigo, para o CAPS ad. Ambos, inadequados à RPb. Assim, a vida fica restrita, pois qualquer ação do usuário pode ser considerada de risco para si ou para os outros. Ao enfatizarmos a cultura de segurança, contraposta ao receio e ao perigo, possibilitamos o debate sobre a noção de cuidado na universidade, na Secretaria Municipal de Saúde e no CAPS ad. Dessa maneira, uma proposta de trabalho foi elaborada e o projeto foi aprovado na Comissão de Ética com Pesquisas Envolvendo Seres Humanos, sob o protocolo no 78900017.4.0000.5151.

Durante a execução das atividades circenses no CAPS ad, as acrobacias na segunda altura sempre impressionaram tanto os profissionais de saúde quanto os usuários. Várias vezes eram feitos comentários que perpassavam a questão da confiança, o grau de responsabilidade e as várias maneiras de tocar o corpo do outro:

Eu vi que pessoas que sempre se comunicaram destes desconhecimentos em termos institucionais, que via até os usuários com esse corpo fragilizado, de uma forma bem recortada, se surpreenderem também positivamente nesse sentido, de falar assim: "Cê viu fulano, está subindo em cima daquela menina, meu Deus, ela é doida" (...) a atividade conseguiu de alguma forma desconstruir esses discursos, essas percepções do sujeito limitado (Referência Técnica, 2017).

$\mathrm{E}$ o $\mathrm{F}$ gente? Ninguém dá nada pelo $\mathrm{F}$. Ele super inteligente. Tinha hora que eu ficava com medo. Meu Deus do céu, a L [pesquisadora] é doida. As coisas que você fazia com ele, se entregava, na confiança... com o F (Usuário do Serviço, 2017).

Através de cuidados mútuos, pesquisadores, usuários e funcionários possibilitaram novas significações para o cuidado em saúde. O termo 
cuidar passa a ser relacionado com fazer segurança de maneira mútua: auxiliando na movimentação; na prontidão para atuar de forma pontual e efetiva, se for necessário; garantindo a integridade física de todos através da cooperação e não pelo receio ou pelo perigo. Para tanto, a cultura circense foi fundamental. Esse cuidado compartilhado envolve, necessariamente, a responsabilidade de cuidar dos outros e se deixar cuidar por eles. Cuidar do outro no circo é imprescindível, não se faz circo sozinho, é regra de segurança e também uma necessidade. Essa noção foi apresentada desde 0 primeiro dia de atividades e, juntos, formamos uma rede de segurança. Na imagem (Figura 1 ) da segunda altura temos, atrás da figura acrobática, o posicionamento de quem cuida.

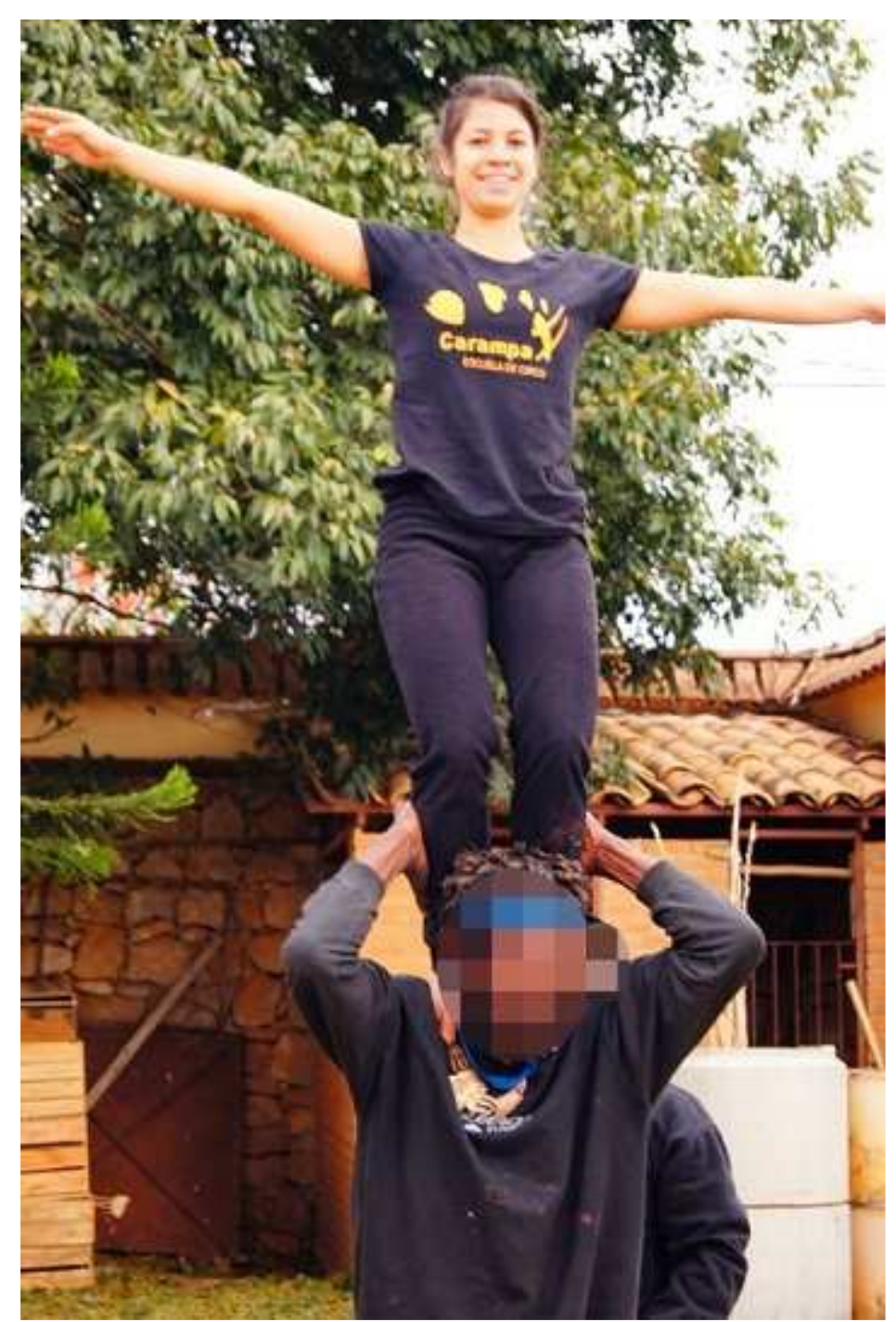

Figura 1. Segunda altura

As atividades circenses desenvolvidas respeitaram as características e interesses individuais, o que implicou em constante reformulação da metodologia e dos exercícios propostos. E, mesmo não visando um 
ideal técnico a ser alcançado, é inegável que ocorreu, de maneira surpreendente, uma grande evolução entre os participantes. As atividades circenses foram desenvolvidas progressivamente a partir de técnicas educativas e das particularidades individuais. Nesse sentido, durante os três meses de trabalho, os vínculos afetivos (Silveira, 1981, 1992) foram ampliados, criando as condições necessárias para o aprendizado e a colaboração.

Escutar as histórias de vida foi extremamente importante nesse processo de integração entre os participantes. E, apesar de as equipes de saúde muitas vezes negligenciarem os aspectos laborais, evidenciando uma dificuldade de integração entre os movimentos de saúde mental e de saúde do trabalhador (Bernardo \& Garbin, 2011), consideramos que esses são aspectos fundamentais nas histórias de vida, tanto para as possíveis correlações com o adoecimento psíquico quanto para as potencialidades no tratamento e, em nosso caso, também para as atividades circenses. Assim, os relatos sobre as funções de pedreiro, serventes, adestrador de cavalos, servidor público, ex-militar, dona de casa, auxiliar de serviços gerais, vendedora, oficineiro, artesão, motorista de caminhão e operador de guincho ganharam espaço e auxiliaram no reconhecimento de cada participante e no modo como cada um se apropria das atividades propostas. Outro fator levado em consideração para a organização das atividades foi a diferença de idade, entre 25 e 70 anos.

Além da diferença etária, outros fatores apontam para a necessidade de se ter consciência sobre os próprios limites. Assim, desde o início, enfatizamos a importância de todos informarem as lesões que tinham sofrido ao longo da vida, bem como dores e incômodos atuais. Assim, ficamos sabendo que vários participantes apresentavam problemas físicos (na coluna, no joelho, no tornozelo e no punho). Tendo consciência sobre os limites e as dificuldades, é possível saber quando é necessário parar e por onde é possível transitar sem danos. No sexto diário de campo, fizemos as seguintes observações sobre as condições físicas de alguns participantes:

(...) segundo os discursos ouvidos nestes seis encontros, os usuários possuem os mais diversos comprometimentos corporais, em função de acidentes variados, muitos envolvendo o uso abusivo de substâncias, outros não. Noutro dia D falou que havia caído de uma barragem com uns 30 metros, ficando mais de seis meses sem andar. V quebrou a tíbia e a fíbula em um acidente de moto, além de ter pino nos punhos e a patela quebrada. $\mathrm{P}$ caiu de 40 metros em uma escalada devido a uma falha técnica e teve sérios comprometimentos. Em outro momento pulou da janela de um apartamento quando fora trancado. T rompeu os ligamentos e tendões da mão, não conseguindo mais dobrar alguns dedos, e constantemente tem 
as pernas, braços e cabeça machucados em virtude das brigas (Diário de Campo, 2017).

Essas informações são extremamente importantes para a criação de metodologias próprias para cada participante, pautadas no respeito pelas diferenças, na possibilidade de autonomia e no cuidado que permeia a cultura circense. Esse respeito pelas diferenças individuais e pelos limites apresentados por cada um foi um dos aspectos que proporcionou o envolvimento de vários participantes nas práticas circenses.

Os encontros de acrobacia, malabarismo e equilibrismo se concretizaram a partir da participação tanto de usuários quanto de funcionários da instituição. O serviço possui um público rotativo, que se altera bastante com o passar dos dias. Conforme as características da instituição, as atividades de circo, no decorrer dos 100 dias, também tiveram um público com bastante rotatividade, foram aproximadamente 40 participantes, sendo que 22 consentiram em colaborar com a pesquisa. Durante as 27 práticas circenses houve variação em relação à frequência dos participantes. Alguns estiveram envolvidos com as atividades do início ao fim. Teve também quem decidiu voltar pra sua terra natal, quem foi tentar novos rumos para a vida em outra cidade. Aqueles que tiveram alta durante o processo e voltaram a trabalhar; aqueles que chegaram à instituição no meio ou perto do encerramento das práticas; teve quem foi preso; quem foi internado; quem recaiu e ainda não tinha voltado. Todos eles, que definitivamente não se traduzem nesses aspectos explicitados, possuem singular importância, afinal de contas, juntos fizemos um laço.

Além dos usuários do serviço, alguns funcionários da instituição se envolveram com as atividades. O vigia (segurança) esteve presente de forma mais efetiva, mostrando grande interesse e potencial. Participaram, também, de maneira mais pontual, a psicóloga, a técnica administrativa e a gerente. Todas com sorriso no rosto, saindo de sua zona de conforto. Para proporcionar um amplo leque de possibilidades de participação, as atividades circenses oferecidas foram bem variadas: acrobacia (de solo e coletiva), malabarismo (bolas, claves, argolas, devilstick e bambolê) e equilibrismo (slackline, rola-rola, latão, perna de pau e monociclo):

Você viu, tem pessoa debilitada aqui ó, que participou da aula de circo. Eu mesmo vi e presenciei, é uma coisa pra todo mundo, é pra todo mundo. Não tem esse ou aquele. Cê viu, tinha uns limitados ali, que mesmo assim tinha coisa pra eles, nem que seja jogar a bola pra cima (Usuário do Serviço, 2017). 
(...) eu acho que foi super tranquilo, porque tinha atividade pra todo mundo, não era 'isso aqui só vai abranger algumas pessoas'. Tinha o que cada uma pessoa conseguia se adaptar ali e tinha pra cada um (Referência Técnica, 2017).

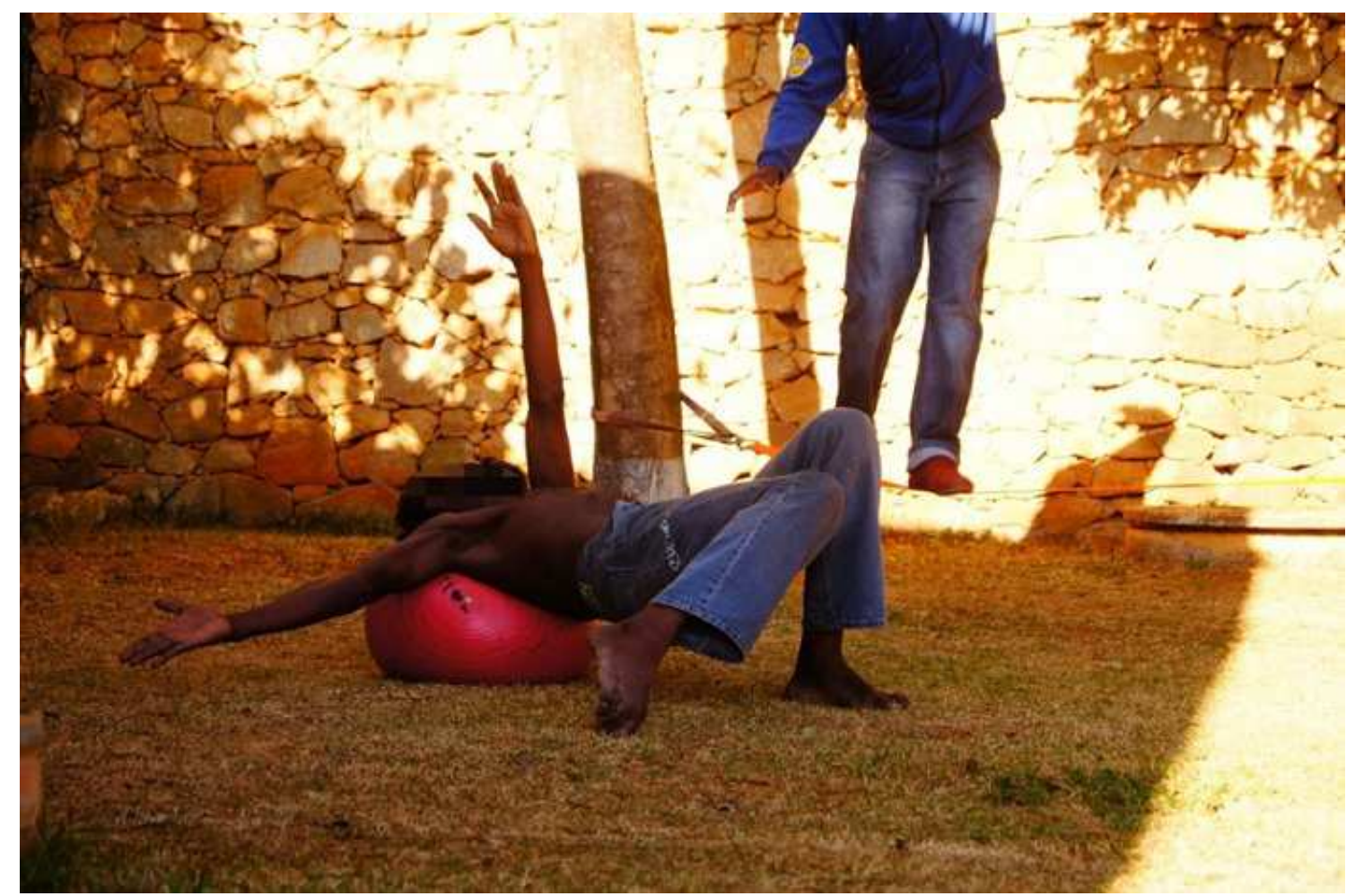

Figura 2. Improviso sobre a bola de equilíbrio e, ao fundo, slackline

Essas observações apontam para a extensão das atividades circenses para além do espaço tradicional do circo, caracterizando o circo social como uma ramificação que enveredou pelo ensino das atividades para grupos em vulnerabilidade. A metodologia pedagógica do circo social foi utilizada por diversos programas ao redor do mundo, como, por exemplo: (1) Women's Circus- criado em 1986, na Austrália, com aulas para mulheres vítimas de agressões sexuais; (2) Circus in Ethiopia - criado em 1991 como ferramenta para prevenir a infecção pelo vírus HIV; (3) Cirque du Monde - criado em 1993, em Quebec/Canadá, pelo Cirque du Soleil, promovendo atividades circenses para jovens de classes populares; e (4), no Brasil, a partir da criação das primeiras escolas de circo na década de 1970, surgiram projetos sociais como ferramenta pedagógica de valorização dos diferentes saberes dos educandos, principalmente crianças e adolescentes em situações de vulnerabilidade (Lafortune \& Bouchard, 2011). Sobre as práticas de circo social no Brasil, afirma Gallo (2010b): 
O circo social atua predominantemente com base nas teorias de Paulo Freire, especialmente no que diz respeito à Pedagogia do Oprimido. Este arcabouço teórico permite aos instrutores/educadores interagirem, no próprio trabalho, com o conceito das diferenças, sejam elas de gênero, etnia ou culturais; diferenças entre educadores e atendidos ou entre projetos e contextos de atuação (p. 28).

O circo social se constitui, portanto, como um caminho para atingir outros objetivos, considerados de relevância social, como a saúde (Lafortune \& Bouchard, 2011). Mas, se as atividades circenses desenvolvidas no CAPS ad se aproximam em alguns aspectos da concepção de circo social, não podemos deixar de levar em consideração as críticas tecidas por Cassoli (2006) sobre o "caráter específico de suas práticas: a filantropia" (p. 26). Dessa maneira, o circo se alia a práticas filantrópicas como maneira de criar novas tecnologias de intervenção social, atendendo ao público que, historicamente, recebeu caridosos auxílios da Igreja e de instituições médicas. As propostas de circo social, segundo o autor, podem provocar, portanto, modos de produzir disciplina, em busca do ser humano correto e/ou curado.

As atividades circenses que desenvolvemos no CAPS ad seguem posição contrária à proposta normatizadora, presente em muitas de nossas instituições de saúde, notadamente de saúde mental. Vale ressaltar que, no momento em que apontamos algumas semelhanças entre a nossa proposta e a noção de circo social, não almejamos nenhum padrão de normalidade e nem mesmo estabelecemos, simplesmente, uma transposição do circo social para a realidade dos serviços de saúde mental. A proposta de circo social serve-nos, apenas, de parâmetro e como possibilidade de reflexão sobre as práticas circenses no campo social, como é o nosso caso. Dessa maneira, podemos estabelecer o contexto para a criação de novas práticas e concepções de cuidado no campo da saúde mental, inseridas no movimento de RPb.

Observamos que as práticas de cuidado em saúde podem estar sob a égide do receio e do temor, produzindo submissão. Assim, o usuário de um serviço de saúde mental passa a ser visto como perigoso para si e para os outros, sendo tutelado e suas ações cerceadas. Mas, se inserirmos a noção de cuidado na perspectiva da RPb, passamos a ter percepções diferentes - ético-filosófica, técnica-instrumental e política -, voltadas para a emancipação do sujeito e para a humanização das práticas assistenciais (Ballarin, Carvalho, \& Ferigato, 2010).

Nesse sentido, podemos dizer que a inclusão das atividades circenses em instituições de saúde mental dialoga com os princípios propostos pela Política Nacional de Humanização - PNH (Brasil, 2003) que, 
através de um conjunto de estratégias, busca alcançar a qualificação da atenção e da gestão no Sistema Único de Saúde (SUS). Logo, a proposta da PNH abre espaço para a construção de saberes interdisciplinares, fundamentais para o desenvolvimento de atividades que se colocam nas regiões de fronteiras entre arte e saúde mental (Melo, 2010b) ou entre saúde e cultura (Melo, 2012).

Em todos os dias de atividades chegávamos ao CAPS com os materiais necessários: equipamento de som, de foto/filmagem, computador, bolinhas, claves, argolas, bambolê, slackline, rola-rola, perna de pau. Além disso, alguns equipamentos ficavam guardados no almoxarifado do CAPS: cesto de bolas, latão, devilstik, outro rolarola e colchonetes. De maneira contrária à submissão aos tratamentos disciplinares, pautados pelo modelo biomédico (Capra, 1982), as atividades circenses propiciaram, pouco a pouco, movimentos de emancipação. Em diversas ocasiões, enquanto os materiais de trabalho ainda estavam sendo levados para dentro do CAPS, o equipamento de som já estava montado, o slackline estava sendo armado e o treinamento havia começado. Esse cuidado com os materiais de trabalho e com a organização das atividades se estendia para o cuidado com a execução das atividades e para a colaboração com o outro, principalmente no aprimoramento das técnicas circenses e no fazer a segurança para o outro. Havia, portanto, envolvimento, autonomia e cooperação:

Se a razão existente aí estiver centrada no 'trabalho vivo', é indicador que a relação entre trabalhador e usuário, para a produção da saúde, se dá sob parâmetros de implicação mútua, no reconhecimento que ali há o encontro de sujeitos que têm juntos protagonismos na produção da saúde e, sobretudo, estão presentes diretrizes de intervenção/relação de acolhimento, estabelecimento de vínculo e responsabilização (Merhy \& Franco, 2003, p. 316). 


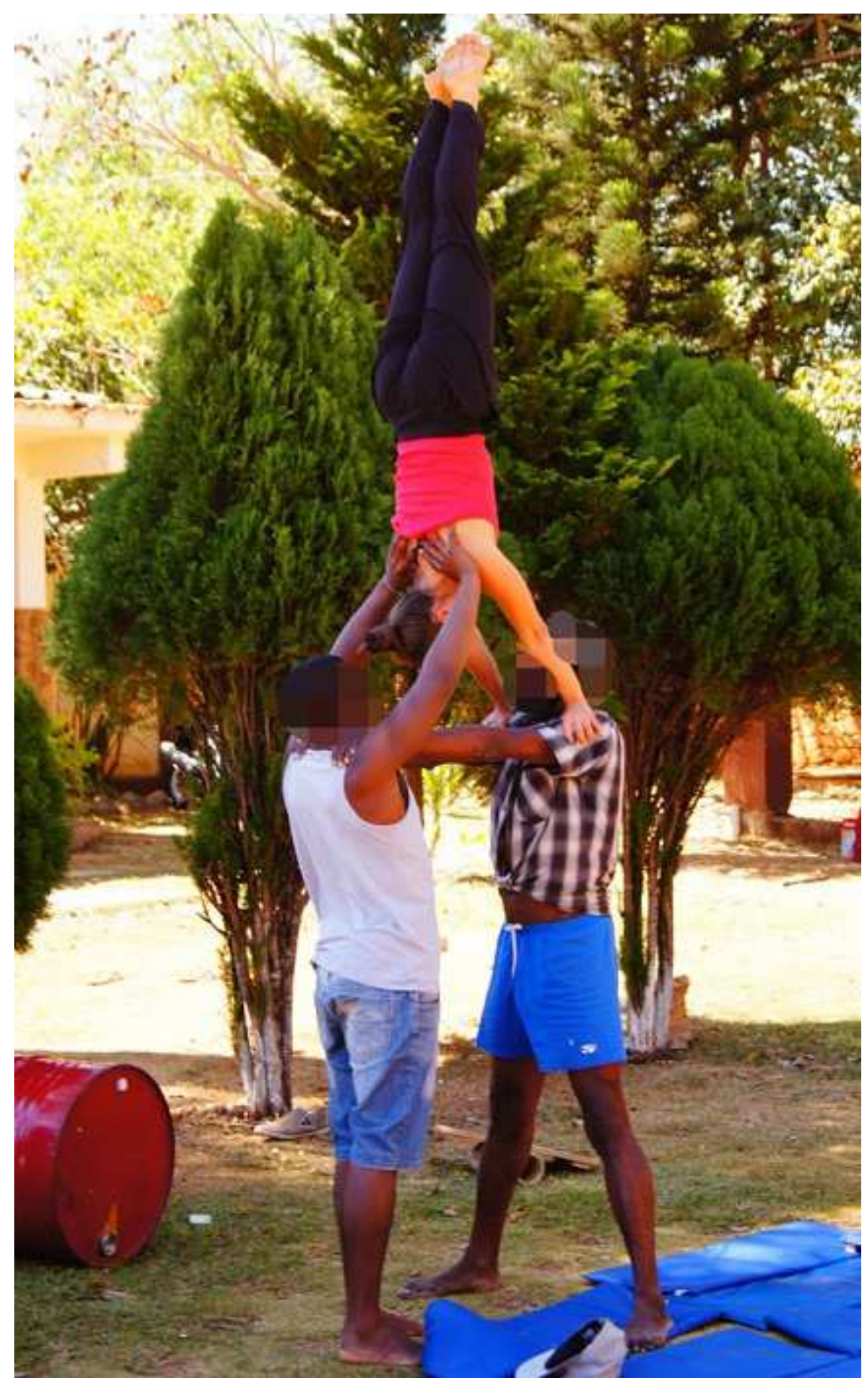

Figura 3. Torre

Segundo Merhy (1997, 1998, 2014), o trabalho vivo em ato se estabelece em processos de relações (tecnologias leves). Entende-se que todo profissional de saúde é um operador do cuidado e que, ao atuar pela perspectivadas tecnologias leves, pode produzir relações de acolhimento, responsabilização e vínculo. Assim, é estabelecido um trabalho que vai além do cumprimento de procedimentos padrões, que se constrói na relação com o usuário, tendo este como protagonista. 
Notou-se que havia uma implicação mútua, de responsabilização e autonomia nas atividades que poderiam estar associadas à noção de trabalho vivo. Um movimento de produção de saúde estabelecido pelo encontro com o sujeito, relacionado ao campo das tecnologias leves (Merhy, 1998; Merhy \& Franco, 2003). A dimensão do afeto mostrou-se como um dos pilares das atividades, pelo qual se estabeleceram relações de trocas, de cumplicidade, de confiança. Os laços estabelecidos possibilitaram realizar um trabalho de campo que ultrapassou seu objetivo principal de praticar atividades circenses, abrangendo várias dimensões do sujeito, da sua relação com o uso de substâncias, com seu próprio corpo, com o tratamento, abordando temas como redução de danos, medicação, trabalho, família, psicoterapia, estruturação do serviço, entre outros.

Eu me identifiquei mais foi com a acrobacia, achei mais interessante, acho mais legal. Você trabalha ter um equilíbrio ali, fortalecimento do corpo. Pra mim trabalha muito mais o corpo que qualquer outro exercício. O malabarismo 'cê' trabalha muito coordenação motora (...). E fisicamente eu acabei criando um pouco mais de resistência, eu tava justamente parado mesmo. Foi um exercício né? Você sai um pouco do sedentarismo, e isso pra mim foi muito bacana, eu senti diferença no meu corpo (Usuário do Serviço, 2017).

Pra ser sincero ela me deu até mais força pra continuar meu tratamento. Porque eu tava pensando até em desistir mesmo. Juntou um monte de coisa né? Eu tinha parado de usar droga, mas pra mim ainda estava usando droga, porque eu tô inútil ainda. Me sinto uma pessoa inútil. Apesar dos pesares, eu ter feito algumas coisas lá em casa, tá ajudando meu pai... mas me sinto meio inútil. No financeiro, porque infelizmente a gente tá numa sociedade que cobra a gente, e isso querendo ou não eu não tenho como escapar (...). E aqui me ajudou também, eu vi que eu era um pouco capaz de fazer as coisas, a acrobacia. Eu tava me sentindo bem zero mesmo, sair de uma vida agitada (...) do nada parei tudo. Tudo na minha vida parou. Aí eu coloquei na balança: o que é melhor? Eu com droga ou eu sem droga? Porque pra mim não tava tendo muito motivo deu ter parado não, muito ganho não. Aí eu comecei a colocar na balança e aí logo você chegou, trazendo essa oportunidade pra gente e eu aceitei bem, né? Eu me entreguei mesmo para essa parte aí e pra mim foi maravilhoso. Me envolvi, e toda segunda e quarta eu fazia questão de tá aqui, porque não é sempre que eu consigo vim (Usuário do Serviço, 2017). 


\section{Considerações Finais}

O percurso desenvolvido busca compreender algumas ressonâncias da inserção da prática de atividades circenses em um serviço substitutivo à lógica manicomial, pautado na atenção psicossocial e em ações territoriais, sendo elas: a relação risco/segurança, evolução técnica e cuidado. Nesse sentido, contrapõe-se ao modelo biomédico, estabelecendo reflexões sobre a noção de cuidado a partir de tecnologias relacionais, evidenciando o trabalho vivo em ato. A base das atividades circenses realizadas no CAPS ad encontra-se, portanto, além das técnicas de circo, nas relações afetivas, na cooperação e no cuidado mútuo. O afeto mostrou-se como um dos pilares das atividades, pelo qual se estabeleceram relações de trocas, de cumplicidade e de confiança, além de possibilitar surpreendentes evoluções técnicas.

A cultura da segurança é um dos elementos fundamentais para a organização de atividades circenses e nos fez refletir sobre o quanto - circo pode ensinar às instituições de saúde mental, nas quais cuidado, muitas vezes, se confunde com receio e temor. Assim, o cuidado mútuo, presente nas atividades circenses, possibilita processos de autonomia, de emancipação e de autocuidado, contrapostos à tutela e à falta de liberdade que pautam o cotidiano de muitos usuários de serviços de saúde mental.

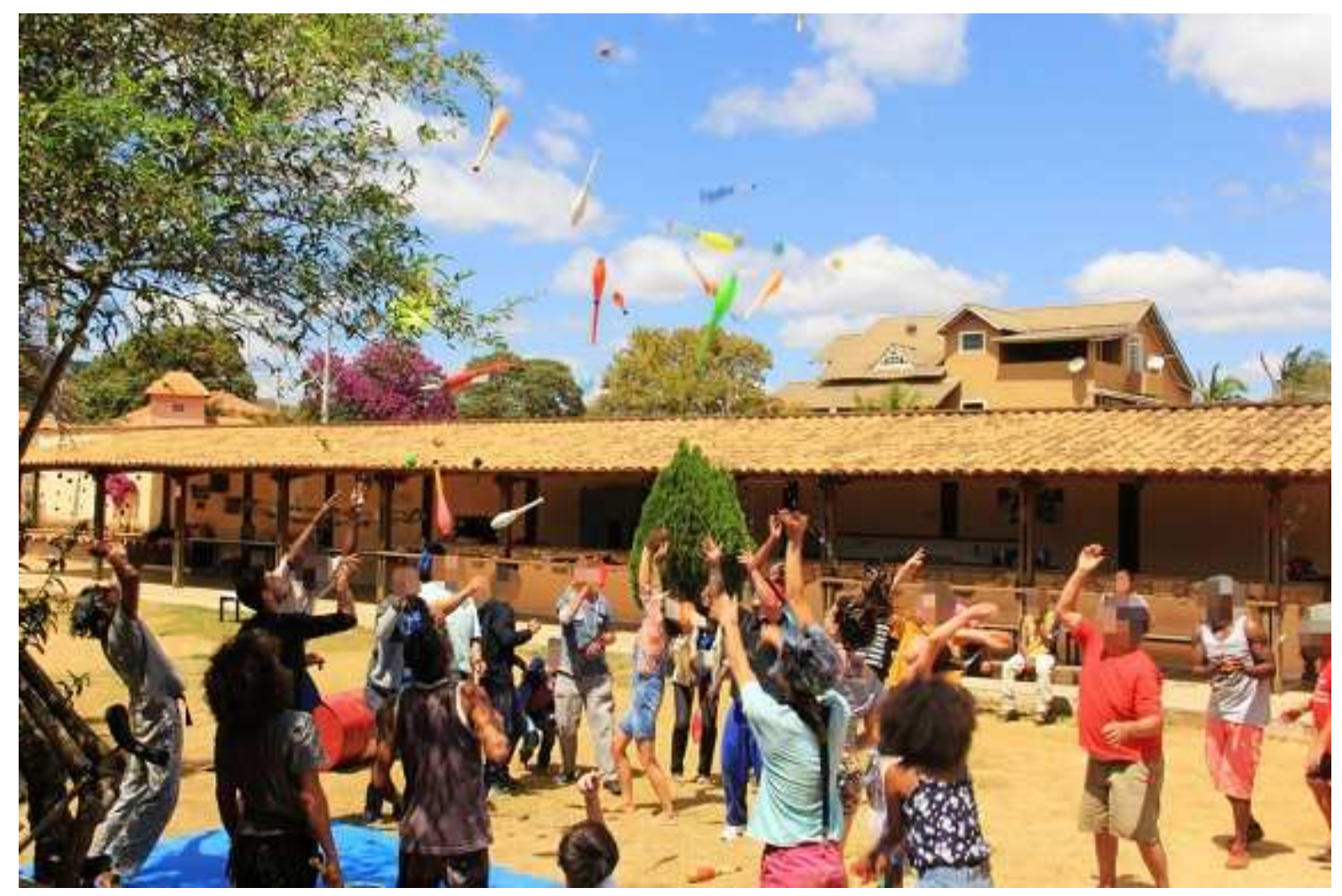

Figura 4. O 'Lançamento', tradicional nos encontros de circo, no encerramento das Práticas Circenses no CAPS ad. 
No circo, fazer a segurança está diretamente relacionado aos atos de cuidado com a integridade do outro, estipulando um cuidado compartilhado. Nesse caso, quem cumpre o papel de segurança função ora exercida por um ora por outro - atuará de acordo com as necessidades para auxiliar no desdobramento da tarefa, diminuindo o risco e servindo de base para as conquistas do outro. Nesse sentido, além da participação de usuários e de profissionais da saúde nas atividades circenses, foi muito significativa a participação do vigia (segurança) da instituição. Inicialmente acostumado ao cuidado e à segurança relacionados aos atos de vigiar, controlar e conter, o segurança colaborou para a construção de novos significados para a noção de cuidado.

Algumas limitações e desdobramentos podem ser pensados a partir do trabalho. O estudo apresenta restrições no que se refere à replicabilidade das atividades, uma vez que exige do profissional o domínio das técnicas circenses para realização das práticas e criação de metodologias individuais. Por ser uma atividade temporária, mesmo que anunciada, constatou-se certa ruptura no cotidiano do serviço, sendo verbalizado por integrantes da instituição o desejo de continuidade das práticas. O fato de se ter acesso a pouco material bibliográfico e a outras experiências documentadas academicamente destaca a importância de se produzir teoricamente e construir diálogos sobre o entrelaçamento das artes circenses e a saúde mental.

Ressalta-se aqui a importância da manutenção e construção de propostas de tratamento que se fundamentam no cuidado em liberdade, no afeto, na relação, na autonomia, sendo inadmissível o isolamento, abusos físicos, mentais e medicamentosos enquanto estratégia para lidar e tratar sujeitos em sofrimento psíquico e/ou que fazem uso abusivo de substâncias. Nesse sentido, compreendese que este trabalho encontra-se alinhado com a Luta Antimanicomial e com a Reforma Psiquiátrica, por ter em sua base um exercício pedagógico centrado na potência da liberdade, construído no encontro, na relação que se estabelece com o sujeito, para além da realização da técnica circense em si. Uma proposta que não pretende se estabelecer aqui enquanto uma forma de tratamento, um modelo, mas que apresenta a maneira como as artes circenses, atreladas aos aspectos citados neste estudo, se mostraram como uma possibilidade de atuação em uma instituição de saúde mental, perpassando a dimensão do cuidado, da produção de saúde, do vínculo, provocando também rupturas no meio acadêmico e no serviço em questão. 


\section{Referências}

Amarante, P. (2007). Saúde Mental e Atenção Psicossocial. Rio de Janeiro: FIOCRUZ.

Assis, J. M. (2010). O riso pela lógica do palhaço na Clinicanálise do sofrimento psíquico grave (Dissertação de Mestrado). Universidade de Brasília, Brasília, DF, Brasil. Recuperado de https://repositorio.unb.br/handle/10482/7003

Avellar, J. C. (2001). A sabedoria que a gente não sabe. Cinemais, (27), 179-203.

Avellar, J. C. (2011). Na fronteira entre a saúde e a não-saúde. In W. Melo \& A. P. Ferreira (Orgs.), A Sabedoria que a Gente Não Sabe (pp. 95-105). Rio de Janeiro: Espaço Artaud.

Ballarin, M. L. G. S, Carvalho, F. B., \& Ferigato, S. H. (2009). Os diferentes sentidos do cuidado: Considerações sobre a atenção em saúde mental. O Mundo da Saúde, 33(2), 218-224. Recuperado de http://www.saocamilosp.br/pdf/mundo_saude/67/218a224.pdf

Barboza, R. P. (2016). Intervenções Riso-Clínicas: Entre palhaços e trabalhadores na educação permanente em saúde mental (Dissertação de Mestrado). Universidade Federal do Rio Grande do Sul, Porto Alegre, RS, Brasil. Recuperado de https://lume.ufrgs.br/handle/10183/157198

Bernardo, M. H., \& Garbin, A. C. (2011). A atenção à saúde mental relacionada ao trabalho no SUS: Desafios e possibilidades. Revista Brasileira de Saúde Ocupacional, 36(123), 103-117. doi:10.1590/S0303-76572011000100010

Brasil. (1988). Constituição da República Federativa do Brasil. Brasíla, D.F.: Presidência da República. Recuperado de http://www.planalto.gov.br/ccivil_03/constituicao/constituicao. htm

Brasil (1990). Lei Federal n. 8080 de 19 de setembro de 1990. Dispõe sobre as condições para a promoção, proteção e recuperação da saúde, a organização e o funcionamento dos serviços correspondentes. Diário Oficial da União. Brasília, D.F.: Presidência da República. Recuperado de http://www.planalto.gov.br/ccivil_03/leis//8080.htm

Brasil (2001). Lei Federal n. 10216 de 6 de abril de 2001. Dispõe sobre a proteção e os direitos das pessoas portadoras de transtornos mentais e redireciona o modelo assistencial em saúde mental. Diário Oficial da União. Brasília, D.F.: Presidência da República. Recuperado de http://www.planalto.gov.br/ccivil_03/leis/leis_2001/l10216.htm

Brasil (2002). Portaria n. 336 de 19 de fevereiro de 2002. Dispõe sobre os Centros de Atenção Psicossocial - CAPS, para atendimento público em saúde mental, isto é, pacientes com 
transtornos mentais severos e persistentes em sua área territorial, em regime de tratamento intensivo, semi-intensivo e não-intensivo. Brasília, D.F.: Ministério da Saúde. Recuperado de

http://bvsms.saude.gov.br/bvs/saudelegis/gm/2002/prt0336_1 9_02_2002.html

Brasil. (2003). HumanizaSUS: Política nacional de humanização. Brasília, D.F.: Ministério da Saúde.

Brasil (2011). Portaria n. 3.088 de 23 de dezembro de 2011. A Rede de Atenção Psicossocial (RAPS) prevê a criação, a ampliação e a articulação de pontos de atenção à saúde para pessoas com sofrimento ou transtorno mental e com necessidades decorrentes do uso de crack, álcool e outras drogas no âmbito do Sistema Único de Saúde (SUS). Brasília, D.F.: Ministério da Saúde. Recuperado de http://bvsms.saude.gov.br/bvs/saudelegis/gm/2011/prt3088_2 3_12_2011_rep.html

Capra, F. (1982). O Ponto de Mutação (Cap. 5, pp. 116-155). São Paulo: Cultrix.

Castro, A. V. (2005). O Elogio da Bobagem: Palhaços no Brasil e no mundo. Rio de Janeiro: Família Bastos.

Cassoli, T. (2006). Do Perigo das Ruas ao Risco dos Picadeiros: Circo social e práticas educacionais não governamentais (Dissertação de Mestrado). Universidade Federal Fluminense, Niterói, RJ, Brasil.

Conceição, A. (2010). Transformando na cena. In W. Melo, F. M. Lopes, M. T. Marchiori; A. G. Martins, D. R. Matos, M. A. Silveira, N. Q. Moreira, \& P. F. Oliveira (Orgs.), Quando Acabar o Maluco Sou Eu (pp. 141-151). Rio de Janeiro: Espaço Artaud.

Dantas, S. M. (2010). A ironia das canções do grupo Harmonia Enlouquece: Estratégia discursiva de enfrentamento ao estigma da loucura (Tese de Doutorado). Universidade Federal Fluminense, Niterói, RJ, Brasil.

Dantas, S. M. (2016). A loucura na canção: Protagonismo e emancipação através da música. Cadernos Brasileiros de Saúde Mental, 8(18), 111-131. Recuperado de http://incubadora. periodicos.ufsc.br/index.php/cbsm/article/vie w/3884/4625

Gadamer, H. G. (2002). Verdade e Método II: Complementos e índice. Petrópolis: Vozes.

Gallo, F. (2010a). A renovação do circo e o circo social. Repertório, (15), 25-29.

Gallo, F. (2010b). O corpo do performer no circo e no circo social. Cadernos do GIPE-CIT, 13(25), 63-70. Recuperado de https://www.circonteudo.com/wp- 
content/uploads/2018/10/Fabio-dal-Gallo-O-Corpo-doperfomer-no-circo-e-no-circo-social.pdf

Gómez, P. A. M. (2017). O corpo em estado de palhaço: Vulnerabilidade e autoconhecimento a serviço do estado de saúde (Dissertação de Mestrado). Universidade Federal da Bahia, Salvador, BA, Brasil.

Lafortune, M., \& Bouchard, A. (2011). Guia do Educador do Circo Social: Das lições do circo às lições da vida. Montreal: Cirque du Soleil.

Mello, L. C. (2014). Nise da Silveira: Caminhos de uma psiquiatra rebelde. Rio de Janeiro: Automática.

Melo, W. (2001). Nise da Silveira. Rio de Janeiro/Brasília: Imago/CFP. Melo, W. (2005). Ninguém Vai Sozinho ao Paraíso: O percurso de Nise da Silveira na psiquiatria do Brasil (Tese de doutorado). Universidade do Estado do Rio de Janeiro, Rio de Janeiro, RJ, Brasil.

Melo, W. (2010a). Nise da Silveira, Fernando Diniz e Leon Hirszman: política, sociedade e arte. Psicologia USP, 21(3), 633-652. doi:10.1590/S0103-65642010000300011

Melo, W. (2010b). Nise da Silveira, Antonin Artaud e Rubens Corrêa: Fronteiras da arte e da saúde mental, Gerais: Revista Interinstitucional de Psicologia, 2(2), 182-191. Recuperado de http://pepsic.bvsalud.org/pdf/gerais/v2n2/v2n2a13.pdf

Melo, W. (2011). O efeito dominó. In W. Melo \& A. P. Ferreira (Orgs.), A Sabedoria que a Gente Não Sabe (pp. 79-94). Rio de Janeiro: Espaço Artaud.

Melo, W. (2012). As regiões de fronteiras do Espaço Artaud: Articulações entre saúde e cultura. Pesquisas e Práticas Psicossociais, 7(2), 211-222. Recuperado de https://ufsj.edu.br/portal2repositorio/File/revistalapip/Volume7_n2/Melo,_Walter.pdf

Melo, W., \& Ferreira, A. P. (2011). A Sabedoria que a Gente Não Sabe. Rio de Janeiro: Espaço Artaud.

Merhy, E. E. (1997). O SUS e um dos seus dilemas: Mudar a gestão e a lógica do processo de trabalho em saúde (um ensaio sobre a micropolítica do trabalho vivo). In S. Fleury (Org.), Saúde e Democracia, a luta do CEBES (pp. 125-142). São Paulo: Lemos.

Merhy, E. E. (1998). A perda da dimensão cuidadora na produção da saúde: Uma discussão do modelo assistencial e da intervenção no seu modo de trabalhar a assistência. In A. T. Reis, A. F. Santos, C. R. Campos, D. C. Malta, \& E. E. Merhy (Orgs.), Sistema Único de Saúde em Belo Horizonte: reescrevendo o público (pp. 103-120). São Paulo: Xamã.

Merhy, E. E. (2014). Saúde: a cartografia do trabalho vivo. São Paulo: HUCITEC. 
Merhy, E. E., \& Franco, T. B. (2003). Por uma composição técnica do trabalho centrada nas tecnologias leves e no campo relacional. Saúde em Debate, 27(65), 316-323. Recuperado de https://www.pucsp.br/prosaude/downloads/territorio/composic ao_tecnica_do_trabalho_emerson_merhy_tulio_franco.pdf

Minayo, M. C. S. (2007). Ciência, técnica e arte: O desafio da pesquisa social. In M. C. S. Minayo (Org.), Pesquisa Social: Teoria, método e criatividade (pp. 9-29). Petrópolis: Vozes.

Moura, R. M. B. (2011). Desfile do 18 de maio em Belo Horizonte: a busca do elemento cultural como possibilidade de transformação dos significados sociais da loucura (Dissertação de Mestrado). Universidade Federal de Minas Gerais, Belo Horizonte, MG, Brasil.

Moura, R. M. B., \& Passos, I. C. F. (2012). O desfile do 18 de maio em Belo Horizonte. Cadernos Brasileiros de Saúde Mental, 4(8), 133-145.

Recuperado de http://incubadora. periodicos.ufsc.br/index.php/cbsm/article/vie $w / 2062 / 2364$

Oliveira, P. F., Melo, W., \& Vieira-Silva, M. (2017). Afetividade, liberdade e atividade: O tripé terapêutico de Nise da Silveira no Núcleo de Criação e Pesquisa Sapos e Afogados. Pesquisa e Práticas Psicossociais, 12(1), 23-35. Recuperado de https://www.academia.edu/38683980/Afetividade_liberdade_e _atividade_o_tripe_terapeutico_de_Nise_da_Silveira20190401_ 77260_1f76xq

Sá, R. C. (2010). Uma experiência teatral para uma cultura antimanicomial. In W. Melo, F., M. Lopes, M. T. Marchiori, A. G. Martins, D. R. Matos, M. A. Silveira, N. Q. Moreira, \& P. F. Oliveira (Orgs.), Quando Acabar o Maluco Sou Eu (pp. 129136). Rio de Janeiro: Espaço Artaud.

Sá, R. C. (2011). Relato de uma experiência Nômade. In W. Melo \& A. P. Ferreira (Orgs.), A Sabedoria que a Gente Não Sabe (pp. 145-150). Rio de Janeiro: Espaço Artaud.

Santos, C. A. (2016). Fascínio Circense: Arte e pedagogia na Escola Nacional de Circo. Belo Horizonte: Rona.

Santos, C.C.G., Belluci, K., Fajtlowicz, R., Bechara, T. S. (2012). A Linguagem Corporal Circense: interfaces com a educação e a atividade física. São Paulo: Phorte.

Silva, C. R. G. G. A. (2012). A arte circense como recurso terapêutico e educacional (Dissertação de Mestrado). Universidade de Trásos-Montes e Alto Douro, Vila Real, Portugal.

Silveira, N. (1981). Imagens do Inconsciente. Rio de Janeiro: Alhambra.

Silveira, N. (1992). O Mundo das Imagens. São Paulo: Ática. 
Wanderley, L. (2011). Grupo de Ações Poéticas Sistema Nervoso Alterado. In W. Melo \& A. P. Ferreira (Orgs.), A Sabedoria que a Gente Não Sabe (pp. 199-200). Rio de Janeiro: Espaço Artaud.

Xisto, V. A. (2009). A desinstitucionalização e as estratégias de sobrevivência dos profissionais de saúde mental nas instituições: "o dia em que quem pirou foi á rua brincar com quem ta pirando" (Dissertação de Mestrado). Universidade do Estado do Rio de Janeiro, Rio de Janeiro, RJ, Brasil.

Xisto, V. A. (2011). "Coletivo carnavalesco Tá pirando, pirado, pirou!": desinstitucionalização e estratégias de sobrevivência dos profissionais de saúde mental. In W. Melo \& A. P. Ferreira (Orgs.), A Sabedoria que a Gente Não Sabe (pp. 181-191). Rio de Janeiro: Espaço Artaud.

Xisto, V. A. (2012). 'Coletivo carnavalesco Tá Pirando, Pirado, Pirou!': desinstitucionalização e estratégias de sobrevivência dos profissionais de saúde mental. Cadernos Brasileiros de Saúde Mental, 4(8), 115-124. Recuperado de http://incubadora. periodicos.ufsc.br/index.php/cbsm/article/vie w/2025/2315

\section{Endereço para correspondência}

Luiza Fernandes Barros

Universidade Federal de São João del-Rei

Departamento de Psicologia

Rua Padre João Pimentel, 80, Dom Bosco, CEP 36301-158, São João Del Rei - MG, Brasil

Endereço eletrônico: bailariza@yahoo.com.br

\section{Walter Melo}

Universidade Federal de São João del-Rei

Departamento de Psicologia

Rua Padre João Pimentel, 80, Dom Bosco, CEP 36301-158, São João Del Rei - MG, Brasil

Endereço eletrônico: wmelojr@gmail.com

Recebido em: 06/03/2019

Reformulado em: 24/06/2019

Aceito em: 16/08/2019

\section{Notas}

* Psicóloga no Centro de Atenção Psicossocial Infantojuvenil de Barbacena/MG; Mestre em Psicologia pela UFSJ; Formada pela Escola Nacional de Circo.

** Coordenador do Núcleo de Estudo Pesquisa e Intervenção em Saúde (NEPIS/UFSJ); Doutor em Psicologia Social pela UERJ; e Pós-Doutorado pela Sorbonne.

Financiamento: CAPES (bolsa de mestrado concedida à primeira autora)

Este artigo de revista Estudos e Pesquisas em Psicologia é licenciado sob uma Licença Creative Commons Atribuição-Não Comercial 3.0 Não Adaptada. 